\title{
Sources of particulate matter components in the Athabasca oil sands region: investigation through a comparison of trace element measurement methodologies
}

\author{
Catherine Phillips-Smith $^{1}$, Cheol-Heon Jeong ${ }^{1}$, Robert M. Healy ${ }^{2}$, Ewa Dabek-Zlotorzynska ${ }^{3}$, Valbona Celo ${ }^{3}$, \\ Jeffrey R. Brook ${ }^{4}$, and Greg Evans ${ }^{1}$ \\ ${ }^{1}$ Southern Ontario Centre for Atmospheric Aerosol Research, University of Toronto, Toronto, Ontario, Canada \\ ${ }^{2}$ Air Monitoring and Transboundary Air Sciences Section, Ministry of the Environment and Climate Change, \\ Etobicoke, Ontario, Canada \\ ${ }^{3}$ Analysis and Air Quality Section, Air Quality Research Division, Environment and Climate Change Canada, \\ 335 River Road, Ottawa, Ontario, Canada \\ ${ }^{4}$ Air Quality Processes Research Section, Air Quality Research Division, Environment and Climate Change Canada, \\ 4905 Dufferin Street, Toronto, Ontario, Canada
}

Correspondence to: Greg Evans (greg.evans@utoronto.ca)

Received: 30 October 2016 - Discussion started: 16 February 2017

Revised: 27 June 2017 - Accepted: 10 July 2017 - Published: 7 August 2017

\begin{abstract}
The province of Alberta, Canada, is home to three oil sands regions which, combined, contain the third largest deposit of oil in the world. Of these, the Athabasca oil sands region is the largest. As part of Environment and Climate Change Canada's program in support of the Joint CanadaAlberta Implementation Plan for Oil Sands Monitoring program, concentrations of trace elements in $\mathrm{PM}_{2.5}$ (particulate matter smaller than $2.5 \mu \mathrm{m}$ in diameter) were measured through two campaigns that involved different methodologies: a long-term filter campaign and a short-term intensive campaign. In the long-term campaign, $24 \mathrm{~h}$ filter samples were collected once every 6 days over a 2 -year period (December 2010-November 2012) at three air monitoring stations in the regional municipality of Wood Buffalo. For the intensive campaign (August 2013), hourly measurements were made with an online instrument at one air monitoring station; daily filter samples were also collected. The hourly and $24 \mathrm{~h}$ filter data were analyzed individually using positive matrix factorization. Seven emission sources of $\mathrm{PM}_{2.5}$ trace elements were thereby identified: two types of upgrader emissions, soil, haul road dust, biomass burning, and two sources of mixed origin. The upgrader emissions, soil, and haul road dust sources were identified through both the methodologies and both methodologies identified a mixed source, but these exhibited more differences than simi-
\end{abstract}

larities. The second upgrader emissions and biomass burning sources were only resolved by the hourly and filter methodologies, respectively. The similarity of the receptor modeling results from the two methodologies provided reassurance as to the identity of the sources. Overall, much of the $\mathrm{PM}_{2.5}$ related trace elements were found to be anthropogenic, or at least to be aerosolized through anthropogenic activities. These emissions may in part explain the previously reported higher levels of trace elements in snow, water, and biota samples collected near the oil sands operations.

\section{Introduction}

The Athabasca oil sands region, located in the north-east corner of the province, is the largest of the three oil sands deposits in Alberta, Canada (Bytnerowicz et al., 2010). This area contains an estimated 1.7 trillion barrels of oil, located tens of meters below the ground (Kean, 2009), composed of a highly viscous mixture of high molecular-weight hydrocarbons, bitumen, clay, sand, and water (Bytnerowicz et al., 2010). As of 2009, the oil was extracted at a rate of 0.825 million barrels per day (Moritis, 2010), predominantly through two methods: open-pit mining and steam-assisted gravity drainage (Canadian Association of Petroleum Pro- 
ducers, 2014). Combined, these methods have rendered $10 \%$ of the bitumen in the oil sands economically recoverable, making Alberta home to the third largest known oil deposit in the world after Venezuela and Saudi Arabia (Xu and Bell, 2013).

The various processes involved in bitumen extraction are believed to have environmental impacts on the area's water (McMaster et al., 2006), soil (Whitfield et al., 2009), and ecology (Goff et al., 2013). While air quality studies are much more limited (Hodson, 2013; Bari and Kindzierski, 2015), gaseous emissions such as $\mathrm{SO}_{2}$ and $\mathrm{NO}_{x}$ are known pollutants associated with oil sands activities (Charpentier and Bergerson, 2009; Bytnerowicz et al., 2010; McLinden, 2012). These gases have been linked to several oil sands extraction processes such as mining, transportation, and upgrading (Howell et al., 2014). Of current interest are aerosol particles below $2.5 \mu \mathrm{m}$ in diameter $\left(\mathrm{PM}_{2.5}\right)$, which affect the environment through transport of pollutants, visibility reduction, and by directly or indirectly shifting the earth's radiation balance (Dusek et al., 2006; Posfai and Buseck, 2010; Jeong et al., 2013). Further, $\mathrm{PM}_{2.5}$ has been linked to adverse health outcomes (Docker et al., 1993; Burnett et al., 1995; Schlesinger, 2007) due to its propensity to penetrate deep down to the alveolar region of the lungs (Borm and Kreyling, 2004; Alfoldy et al., 2009). $\mathrm{PM}_{2.5}$ is produced both by natural and anthropogenic sources such as motor vehicles, windblown dust, industrial processes, and biomass burning (Jeong et al., 2013). Past research on $\mathrm{PM}_{2.5}$ within the Athabasca region has included overall and comparative emission and air quality analyses (Kindzierski and Bari, 2011, 2012; Wang et al., 2012, 2015; Percy et al., 2012; Howell et al., 2014; Landis et al., 2017). Further studies have developed into modeling the emission sources through both computer-based (Cho et al., 2012) and measurement-based methods (Landis et al., 2012)

No previous studies have examined short-term variability in the elemental composition of $\mathrm{PM}_{2.5}$ in this region. However, compositional analysis of $\mathrm{PM}_{2.5}$ has helped elucidate sources and processes that contribute to $\mathrm{PM}_{2.5}$ mass concentrations in other regions. Trace element species in $\mathrm{PM}_{2.5}$ are of particular importance because they can be sourcespecific and are typically preserved in the aerosol phase during transport. For example, $\mathrm{V}$ and $\mathrm{Ni}$ are often indicative of oil combustion (Becagli et al., 2012) as well as oil derivatives (Shotyk et al., 2016), while $\mathrm{Al}, \mathrm{Mg}$, and $\mathrm{Cr}$, when grouped together, have been indicative of dust in the past, specifically that associated with transportation (Amato et al., 2014). This source specificity allows for the identification of sources of $\mathrm{PM}_{2.5}$ with great resolution (Moreno et al., 2009). Receptor models are often used to determine these sources in areas where the chemical composition of the various sources is unknown. One such receptor model is positive matrix factorization (PMF), which uses a weighted multivariate statistical approach to identify pollution sources (called factors) by examining the correlations in the $\mathrm{PM}_{2.5}$ speciation matrix over time (Paatero, 1996). In past receptor modeling, openpit mining, upgrading, and fugitive dust have been identified as major emission factors in the oil sands region (Landis et al., 2012; Bari and Kindzierski, 2017). However, these emission factors were identified based solely on long-term, low time-resolution data.

Previous studies also provide indirect indications of higher levels of trace elements $\mathrm{s}$ in this region. Through dry and wet deposition, such as snowfall (Bari et al., 2014), it is possible for the trace elements contained in the particulate matter to reach the soil and surface waters in the area (Amodio et al., 2014). Metals, such as $\mathrm{Cu}, \mathrm{Zn}, \mathrm{Ni}, \mathrm{Cr}$, and $\mathrm{Pb}$, have been found to be higher in the Athabasca River, its tributaries, and snowpack near the oil sands developments than several hundred kilometers away (Kelly et al., 2010). Furthermore, epiphytic lichens have experienced increases in $\mathrm{Ti}, \mathrm{Al}, \mathrm{Si}$, and $\mathrm{Ba}$ (Landis et al., 2012). In summary, the available evidence suggests that contamination may already be occurring in this region and that some of this may be due to the transport of trace elements present within $\mathrm{PM}_{2.5}$.

Due to these gaps in knowledge, the purpose of this work was threefold: (1) to fill the knowledge gaps that exist about the sources of $\mathrm{PM}_{2.5}$ trace elements in this region; (2) to assess the accuracy, precision, and consistency of the Xact $^{\mathrm{TM}} 625$ instrument (Cooper Environmental Services, OR, USA) used for the intensive hourly measurements versus that of the more standard $24 \mathrm{~h}$ filters; and (3) to determine what can be learned from receptor modeling using higher timeresolved vs. $24 \mathrm{~h}$ filter data.

Since December 2010, under the Enhanced Deposition Component of the Joint Canada-Alberta Implementation Plan for Oil Sands Monitoring (JOSM) Program, 24h integrated filter samples have been collected by Environment and Climate Change Canada in $\mathrm{PM}_{2.5}$ at three sites (Fig. 1) operated by the Wood Buffalo Environmental Association (WBEA). As part of a 2013 summer intensive field campaign, hourly measurements were also made at one of the sites (Fort McKay South, AMS13) for 1 month (10 August10 September) using a semicontinuous metal monitoring system. A comprehensive protocol was developed to analyze the data from the two methodologies individually with PMF, which made it possible to identify the sources of $\mathrm{PM}_{2.5}$ affecting the measurement sites (Jeong et al., 2013, 2016; Sofowote et al., 2014). The identity of these sources was supported by comparing the resolved source profiles with existing profiles for the postulated sources along with temporal patterns of measured gaseous species. Meteorological data (courtesy of the WBEA) were used to further improve interpretation and identify probable source locations. By comparing the PMF results of the $24 \mathrm{~h}$ and hourly measurements, a deeper understanding of the long- and short-term temporal variability of the sources and the applicability of the two measurement methodologies to receptor modeling was achieved. 


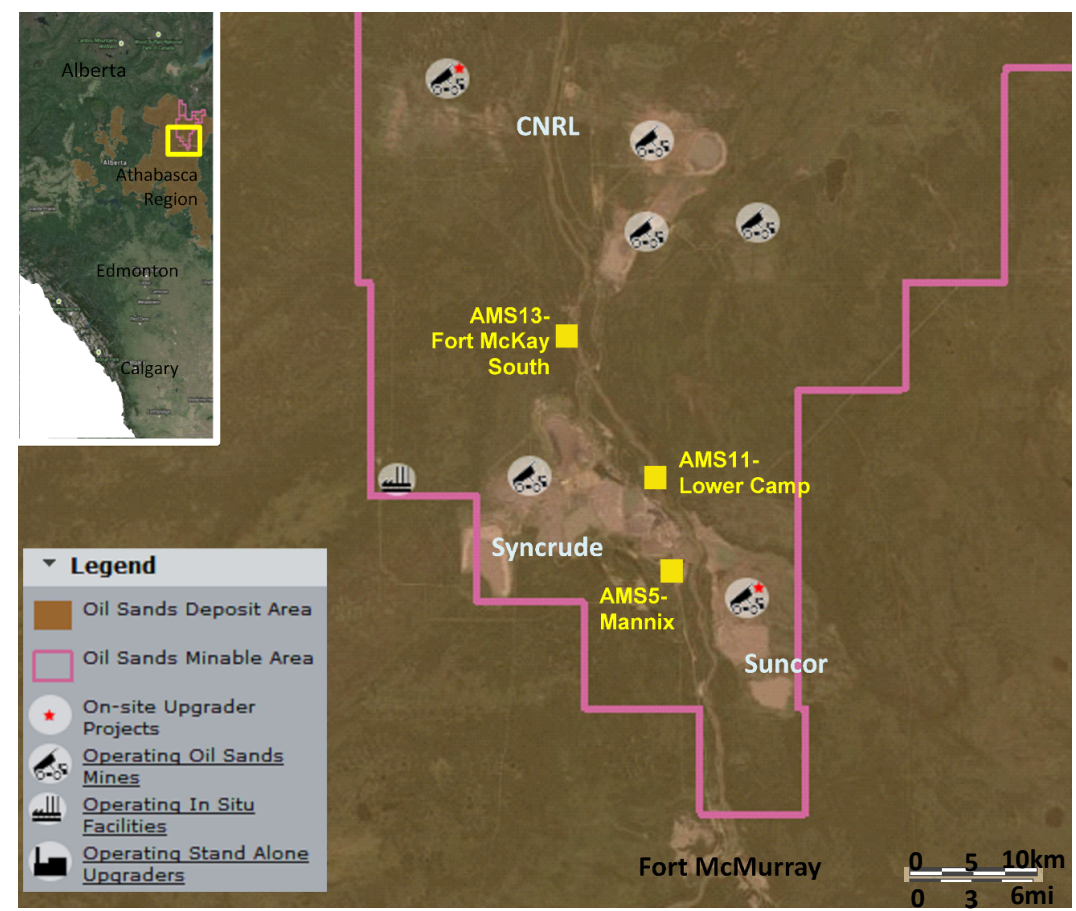

Figure 1. Locations of the various extraction processes and three measurement sites (triangles) within the municipality of Wood Buffalo in the Athabasca region of Alberta, Canada. Map courtesy of Alberta's Environmental and Sustainable Resource Development. Available at http://osip.alberta.ca/map/.

\section{Methods}

\subsection{Field measurement sites}

Under the Air Component of JOSM, the municipality of Wood Buffalo was selected for the monitoring of air pollutants associated with oil sands activities because it is home to both mining and in situ extraction operations. In the long-term filter study, element concentrations were monitored around the Athabasca river valley at three WBEA air monitoring stations (AMSs): AMS13 - Fort McKay South (SYN); AMS5 - Mannix (MAN); and AMS11 - Lower Camp (LOW) (Fig. 1). The AMS13 site is located between three oil companies in the area, all of which perform extensive mining, upgrading, and in situ processing (Fig. 1): Canadian Natural Resources Limited (CNRL) is to the north, Syncrude is to the south, and Suncor is to the southeast. All three companies extract bitumen through both open-pit mining and in situ methods within the Athabasca region. The other two measurement sites are located farther south, directly between Syncrude and Suncor, with AMS11 to the north of AMS5.

Within the municipality of Wood Buffalo, open-pit mining is the predominant method of bitumen extraction. In open-pit mining, large hydraulic shovels lift the oils sand into trucks for transport to a nearby wet crusher which reduces the size of the soil and adds water, allowing the soil slurry to be piped to an upgrading facility (Syncrude Canada Ltd., 2017; Canadian Association of Petroleum Producers, 2014). Once at the upgrading facility the bitumen is separated from the slurry in large settling vessels, after which it is upgraded into different hydrocarbon streams using steam, vacuum distillation, fluid cokers, and hydrocrackers; these processes produce aerosol particles which are emitted to the air through both the main stack (Landis et al., 2012) as well as numerous other secondary stacks. Within these stacks, some particles are directly emitted from the upgrading processes, while others are created by the pollution control devices installed within the stacks (Wang et al., 2012). Other known sources of particles are the large fleets of on- and off-road vehicles, dust resuspended by mining activities, windblown dust from the tailings ponds and dikes (Wang et al., 2015), and dust resuspended from open petroleum coke piles.

\subsection{Instrumentation}

\subsubsection{Filter monitoring setup}

$\mathrm{PM}_{2.5}$ samples were collected at the three sites on $47 \mathrm{~mm}$ polytetrafluoroethylene (PTFE) membrane filters (Pall Corporation, New York) using Thermo Fisher Partisol 2000FRM samplers at $16.7 \mathrm{~L} \mathrm{~min}^{-1}$. The samplers were operated once every 6 days with a $24 \mathrm{~h}$ sampling time (midnightmidnight) according to the National Air Pollution Surveillance (NAPS) protocol. All samples, including laboratory, travel, and field blanks, were subjected to gravimetric determination of PM mass and were subsequently an- 
Table 1. Summary of the measurement strategy used during the two campaigns.

\begin{tabular}{|c|c|c|c|c|}
\hline \multirow[t]{2}{*}{ Campaign } & \multirow[t]{2}{*}{ Sampling interval } & \multicolumn{3}{|c|}{ Monitoring site } \\
\hline & & AMS5 & AMS11 & AMS13 \\
\hline Long-term filter (Dec 2010-Nov 2012) & $24 \mathrm{~h}$ integrated filters (once every 6 days) & ED-XRF/ICP-MS & ED-XRF/ICP-MS & ED-XRF/ICP-MS \\
\hline Intensive filter (13 Aug-10 Sep 2013) & $23 \mathrm{~h}$ integrated filters (daily) & NA & NA & ED-XRF/ICP-MS \\
\hline Intensive (10 Aug-5 Sep 2013) & $1 \mathrm{~h}$ continuous & NA & NA & Xact metals monitor \\
\hline
\end{tabular}

alyzed for 22 elements using nondestructive X-ray fluorescence (ED-XRF). $\mathrm{PM}_{2.5}$ samples were then analyzed for 37 trace elements including 14 lanthanoids by inductively coupled plasma mass spectrometry (ICP-MS) combined with microwave-assisted acid digestion, which provides superior detectability for trace metal(oids) (Celo et al., 2011). A comparison of overlapping elements (i.e., $\mathrm{Al}, \mathrm{Ti}, \mathrm{V}, \mathrm{Mn}, \mathrm{Fe}$, and $\mathrm{Zn}$ ) measured by both ICP-MS and ED-XRF (Fig. S3f in the Supplement) confirmed good agreement with correlation coefficients $\left(r^{2}\right)$ from 0.81 to 0.96 . The PMF analysis applied 2 years of filter data from 16 December 2010 to 29 November 2012 (long-term filter; Table 1).

\subsubsection{Intensive-campaign setup}

During the intensive campaign in August 2013, daily $\mathrm{PM}_{2.5}$ samples were also collected at the AMS13 site using a dichotomous sampler (Partisol 2000-D, Thermo Scientific, Waltham, MA) on $47 \mathrm{~mm}$ PTFE filters (Pall Corporation, New York). The sampler was operated with a $23 \mathrm{~h}$ sampling time (08:30-07:30 MST) so as to allow an hour for filter switching. In the dichotomous PM sampler, a virtual impactor splits the incoming $\mathrm{PM}_{10}$ sample stream into fine $\left(\mathrm{PM}_{2.5}\right)$ and coarse $\left(\mathrm{PM}_{10-2.5}\right)$ fractions. Mass flow controllers maintained the flow rates of the fine and coarse particle streams at 15 and $1.7 \mathrm{~L} \mathrm{~min}^{-1}$, respectively. Elemental composition of $\mathrm{PM}_{2.5}$ was analyzed following the procedure described above. Due to the limited number of samples taken (sample number $n=29$ ), these $\mathrm{PM}_{2.5}$ data were combined with those of the long-term campaign for PMF analysis.

In addition to the filter measurements, an Xact 625 (Cooper Environmental Services) made hourly measurements of 23 element 1 species at AMS13 between $10 \mathrm{Au}$ gust and 5 September $2013(n=489)$. This semicontinuous instrument was installed in a trailer and sampled air through a $\mathrm{PM}_{10}$ head fitted with a $\mathrm{PM}_{2.5}$ cyclone located $4.55 \mathrm{~m}$ above ground level. The Xact instrument used a twostep semicontinuous process. In the first step, particles were pumped through a section of PTFE filter tape at a flow rate of $16.7 \mathrm{~L} \mathrm{~min}^{-1}$, which was regulated through measurement of the inlet temperature and pressure. The section of filter tape was then analyzed in the second phase, which employs the same measurement technique as ED-XRF. Both the sampling and the measurement phase occurred simultaneously, producing data for all 23 element s every hour.

\subsection{Quality assurance and quality control}

The filter measurements were carried out in accordance with the standard operating protocols that were in place and care was taken to ensure that quality assurance and control programs (ISO17025 accredited) were followed.

Quality assurance and quality control (QA/QC) for the Xact measurements was based on protocols implemented before, during, and after the intensive campaign. Prior to the intensive campaign, the Xact instrument was calibrated using 12 high-concentration metal standards. Three metal standards: $\mathrm{Cr}, \mathrm{Pb}$, and $\mathrm{Cd}$, were selected to represent the three energy levels employed by the Xact instrument. These metal standards were measured on-site at the beginning of the intensive measurement campaign (Table S1 in the Supplement). Throughout the campaign, the internal $\mathrm{Pd}, \mathrm{Cr}, \mathrm{Pb}$, and $\mathrm{Cd}$ upscale values were recorded after the instrument's daily programmed test, and the $\mathrm{PM}_{10}$ and $\mathrm{PM}_{2.5}$ cyclones were cleaned weekly. A sample of filtered air was measured daily to determine both the detection limits (DLs) and baseline biases of the metals the instrument measured. Further QA/QC that occurred during the campaign can be found in the Supplement. After the campaign, the performance of the Xact metals monitor was further evaluated through three methods: re-testing with the high-concentration standards and new medium-concentration standards, as well as a comparison of the Xact data to co-measured data from filter samples and other collocated high time-resolution instruments (Supplement Sect. S1).

\subsection{Data analysis}

\subsubsection{Positive matrix factorization}

The element speciation data of the two measurement methods were analyzed using positive matrix factorization (PMF). Developed by Paatero and Tapper, PMF is a least squares regression model that inputs the data $(X)$ and uncertainty $(\sigma)$ matrices of the receptor site, resolving them into factor profiles $(F)$, factor contributions $(G)$, and residuals $(E)$ (Paatero and Tapper, 1993, 1994) (Eq. 1). Each factor corresponds to pollution sources or processes that may co-occur, contributing to particles at the receptor site; the profile displays the concentration of element species within each factor, and the time series displays the normalized contribution of each factor to the total element concentration over time (Norris and 
Duvall, 2014).

$X=G F+E$

Marker elements within the factor profiles were identified based on their high concentrations and/or percent segregations. These marker elements enabled the initial attribution of these PMF factors to probable sources. The identity of these sources was then supported by comparing, where possible, the resolved PMF profiles with source profiles for the suspected sources along with temporal patterns of measured gaseous species.

Prior to running the PMF algorithm, the data were screened to exclude elements for which fewer than $10 \%$ of the measurements were above the DL (Table S2). The data for elements measured with both ED-XRF and ICP-MS were then compared so as to select the optimal set of measurements based on the percentage of data above the DL and the signal-to-noise ratio $(S / N)$. For a full description of the PMF algorithm and pretreatment, refer to Sect. S2. The diversity of the elements among the factors was examined using Shannon entropy (Healy et al., 2014) (Sect. S5). Elements with a diversity value greater than 3.5 were discounted as marker elements in the factor profiles due to their relatively equal segregation into the different factors.

The filter and Xact data were analyzed separately using PMF due to their different sampling intervals. Filter data from December 2010 to November 2012 (long-term filter) and August 2013 (intensive filter) were combined (total $n=$ 351) to produce a single data matrix as the August 2013 data alone were insufficient to support a separate PMF analysis. Measurements taken by ICP-MS were combined with those taken by ED-XRF in order to create a full element profile. In instances where the ICP-MS and ED-XRF both measured the same species, the data measured by ICP-MS were selected as this resulted in the most above-DL data. PMF solutions with four to six factors were considered as candidates and fivefactor solutions were selected for both the filters and the Xact data; these solutions had three common factors and two factors that differed (Figs. S5-S7). Furthermore, the five-factor solution for the combined filter data was similar to five-factor solutions produced when the filter data from each site were run independently (AMS5, AMS11, and AMS13) (Sect. S3).

In order to estimate uncertainties and evaluate the robustness and rotational ambiguity of PMF modeling results, the solutions were evaluated using the error estimation methods of EPA PMF 5; bootstrap analysis (BS), displacement analysis (DISP), and bootstrap enhanced by displacement (BS-DISP). Bootstrap analysis (BS) was performed to quantify the uncertainty of a PMF-resolved solution. In addition, 100 bootstrap iterations were conducted to obtain the percentage of factors assigned to each base case factor (i.e., bootstrap mapping) and determine unstable factors in the PMF solutions. With the displacement analysis (DISP), each element in the source profile is displaced from its fitted value in a PMF solution to estimate the uncertainties for each element in each factor profile. Based on the result of the displacement analysis of a PMF solution, the rotational ambiguity of PMF solutions was assessed (i.e., the number of swaps at the lowest predetermined $Q$ levels). BS-DISP, a combination of BS and DISP, estimates the error associated with both random and rotational ambiguity (Paatero et al., 2014; Brown et al., 2015). A discussion of diagnostic results of the error estimation methods for possible PMF solutions is provided in Sect. S3.

\subsubsection{Supporting analyses}

To further investigate the results, linear regression analyses were performed for each factor time series against $\mathrm{NO}, \mathrm{NO}_{2}$, $\mathrm{NO}_{x}$, and $\mathrm{SO}_{2}$ concentrations (obtained from the Wood Buffalo Environmental Association) in order to identify relationships. Spearman ranked correlation analysis was performed on the comparison of temporal variations, whereas an uncentered correlation coefficient was used to evaluate the level of similarity between factor profiles. The time series of each factor resulting from both methodologies were run through a conditional probability function (CPF) to determine the most likely direction of the relevant sources. As described in Eq. (2), the CPF is the ratio between the number of times the mass contribution surpasses a certain threshold percentile (i.e., $75 \%$ ) when the wind comes from a certain direction $\left(m_{\Delta \theta}\right)$ and the number of times the wind came from that direction $\left(n_{\Delta \theta}\right)$ (Kim and Hopke, 2004).

$\mathrm{CPF}=\frac{m_{\Delta \theta}}{n_{\Delta \theta}}$

In this study, the wind direction (obtained from the WBEA) was divided into 24 bins, each encompassing $15^{\circ}$, and time periods with wind speeds below $1 \mathrm{~m} \mathrm{~s}^{-1}$ were removed. Given the varied topography within the Athabasca River basin, favoring transport of local emissions along the river valley, the CPF only gave approximate indications of the source directions. Finally, a back trajectory model, Hybrid Single-Particle Lagrangian Integrated Trajectory (HYSPLIT), was run on potential nonlocal factors (Stein et al., 2015).

\section{Results and discussion}

\subsection{Elemental species overall trends}

Average element concentrations from the filter data were compared to measurements taken by the NAPS program at seven different Canadian sites (Environment and Climate Change Canada, 2015) (Table S6), which, due to a lack of comparable rural or remote baseline data, corresponded to different Canadian cities. Prior to averaging, blank values were removed as described in Sect. S2, and below detection limit (BDL) values were replaced by half the detection limit. 
Overall, the average concentrations of some of the elements measured through the long-term campaign were lower than those observed at the sites as shown in Table S6. This is not overly surprising as the cities are impacted by a range of anthropogenic activities such as heavy traffic and industrial factories. What was surprising was the number of elements measured in the largely unpopulated oil sands region, which exhibited similar or higher concentrations to those seen across the various sites. In particular, levels of $\mathrm{Si}, \mathrm{Ti}, \mathrm{K}, \mathrm{Fe}, \mathrm{Ca}$, and $\mathrm{Al}$ appeared to be higher near the oil sands operations. However, these averages do not fully capture the differences between the sites and the oil sands region. In the oil sands, large swaths of forest are broken up by the occasional mine or upgrader. When the wind comes from one of these directions, particularly the upgraders, there is a noticeable difference in the air quality. To illustrate this large variability, the 90th percentile of the various elements was calculated and analyzed, as species that show a high degree of variability are more likely to be from these intermittent pollution sources. The results of this showed that the previously discussed elevated elements showed peaks indicating large variability. Additionally, at the highest peaks the concentrations of $\mathrm{S}, \mathrm{Ba}, \mathrm{Br}$, and $\mathrm{Mn}$ also showed large increases, which indicates that in the oil sands, they are likely caused by anthropogenic sources.

\subsection{PMF results}

Each technique identified five unique factors through PMF analysis. Comparison of these factors led to the identification of seven factors: two types of upgrader emissions, soil, haul road dust, biomass burning, and two factors of presumably mixed origins. Three of these factors were identified by both methodologies and two by only one of the methodologies, and the two mixed sources showed more differences than similarities between the two methodologies. The results of the PMF factor profiles (F matrix) from the two methodologies can be seen in Fig. 2 (hourly data from the intensive campaign in August 2013) and in Fig. 3 (24 h filter data from the combined long-term campaign, December 2010-November 2012, and intensive filter campaign in August 2013). Distinctive marker elements were evident in some profiles while other elements were surprisingly ubiquitous, appearing in most or all of the factors. Here the high diversity of $\mathrm{Ni}$ and $\mathrm{Se}$ across the source profiles is interesting as it implies that these metal(oid)s are present in most of the sources, perhaps as a result of greater natural homogeneity in this region or contamination of the region through anthropogenic activities.

\subsubsection{Upgrader emissions I}

This factor was attributed to typical emissions from the upgrading processes based on the correlation (uncentered $r=$ 1.00 for the intensive campaign (Fig. 2): uncentered $r=1.00$ for the long-term campaign; Fig. 3) of its elemental profile

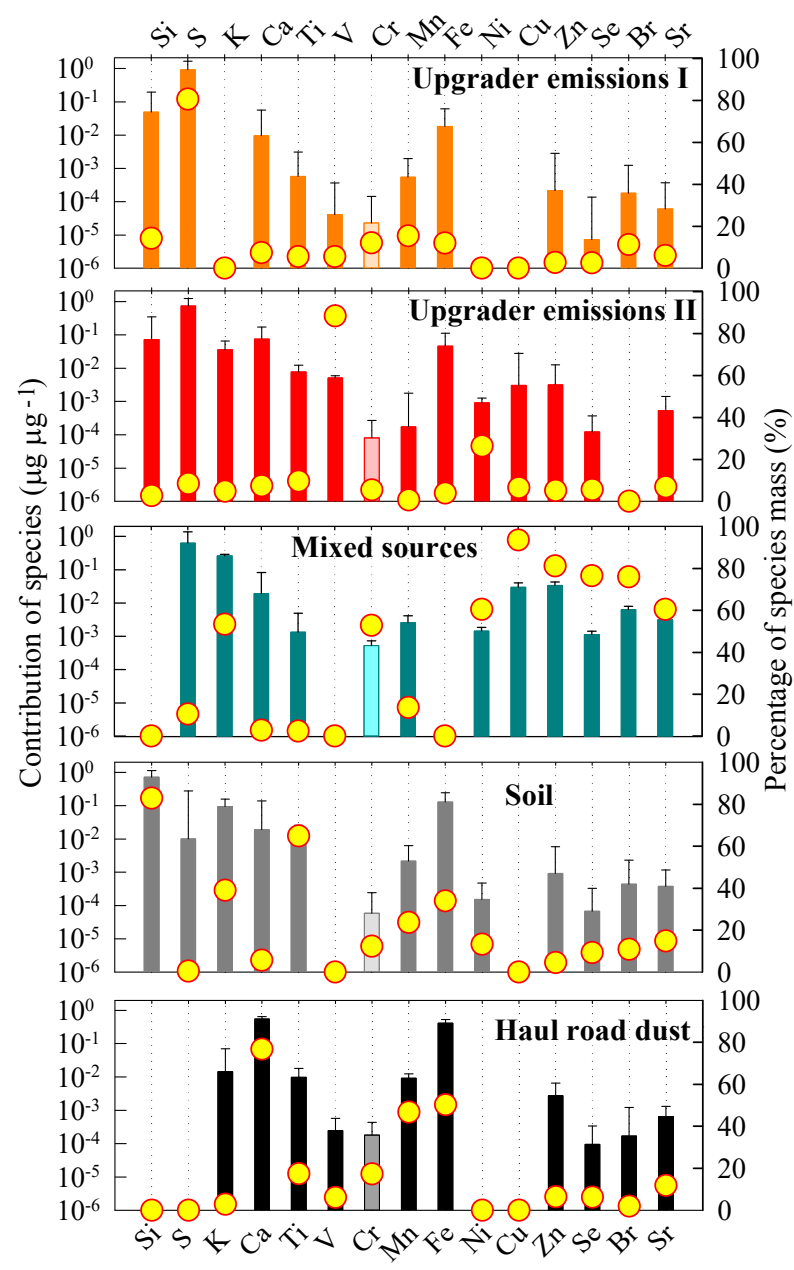

Figure 2. Factor profiles from the hourly measurements by the Xact instrument, 10 August-5 September 2013. The percentage of species is defined as the percentage of mass of each element apportioned to each factor. Factor concentrations depicted as bars, percentages depicted as circles. Error bars represent standard deviations estimated by 100 bootstrap runs. Elements with diversity values above 3.5 have been given a higher transparency than the remaining elements.

with an average profile derived from samples of $\mathrm{PM}_{2.5}$ taken from main upgrader stacks in the area (Landis et al., 2012). Specifically, the elemental profile contained significant portions of the $\mathrm{S}, \mathrm{V}, \mathrm{As}, \mathrm{Br}$, and $\mathrm{Pb}$ (Fig. 3). The very high $\mathrm{S}$ contribution in its profiles distinguished it from the second upgrader-related factor. The profile is suggestive of a mixedcombustion source (Lee et al., 2000; Van Loo and Koppejan, 2008), such as coke, or the process gasses, which are comprised of effluent from the sulfur recovery units (Wang et al., 2012). Further, the high correlation of this factor with $\mathrm{SO}_{2}$ (Table 2) was consistent with the increased $\mathrm{SO}_{2}$ observed in fresh industrial plumes in the area (Hsu and Clair, 2015; Zhang et al., 2015). There were strong correlations in (i) the PMF factor profiles derived from the two methodologies and 


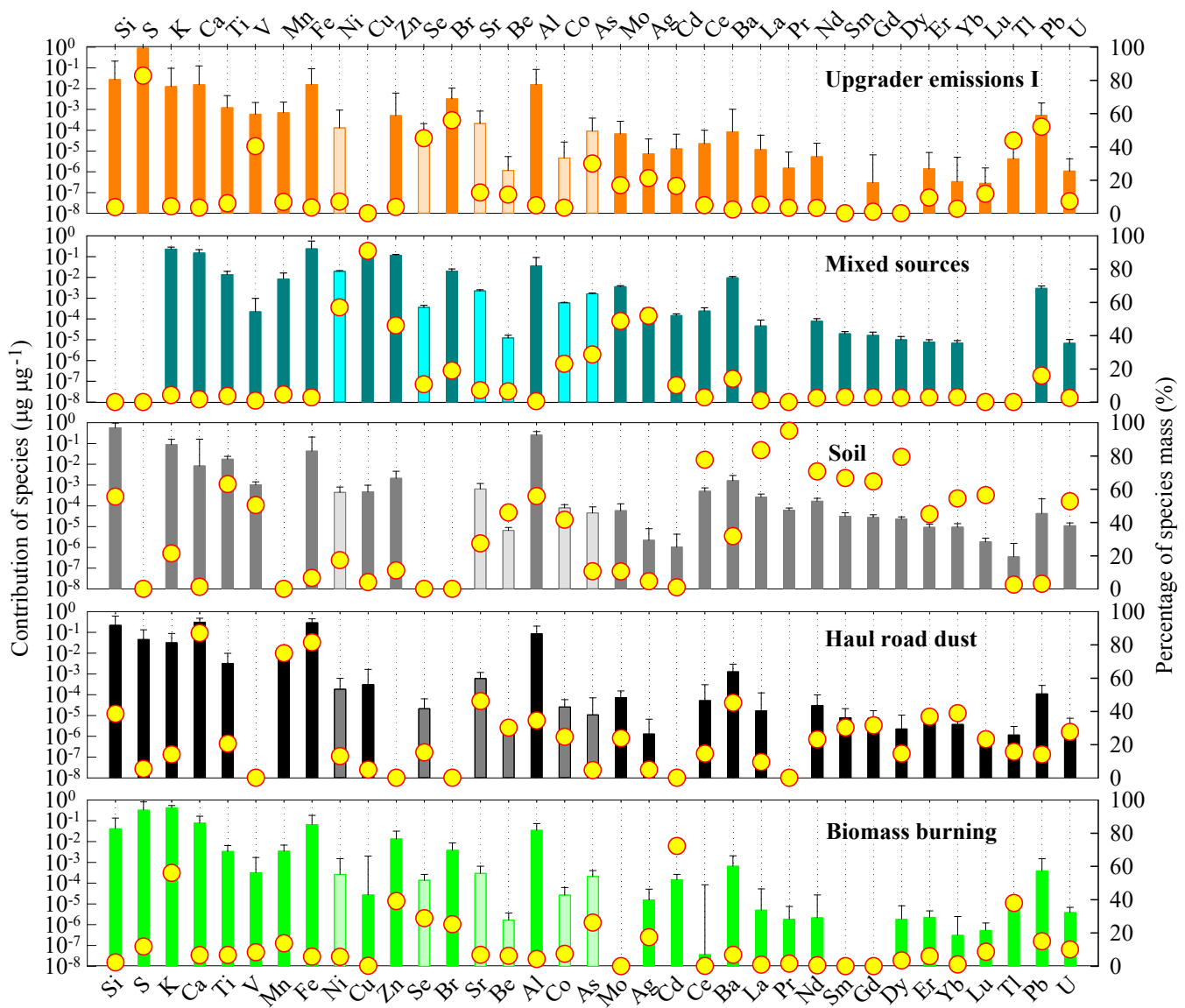

Figure 3. Factor profiles of the combined filter data. Filters were collected once every 6 days at three sites for 2 years (December 2010 November 2012) and daily at one site in August 2013. Factor concentrations depicted as bars; percentages depicted as circles. Error bars represent standard deviations estimated by 100 bootstrap runs. Elements with Shannon entropy below 3.5 have been given a higher transparency than the remaining elements.

(ii) the time series between the co-measured Xact and filter data of this factor (profile (uncentered $r=1.00$ ); time series (Spearman $r=0.74, p<0.01)$ ). These observations support the assertion that this factor resulted from the combustion of a range of fuels in support of upgrading processes.

\subsubsection{Upgrader emissions II}

This factor was hypothesized to be a less common type of emissions originating from upgrading processes; it was only resolved through the hourly data of the intensive measurement campaign. More specifically, this factor was attributed to oil- or bitumen-based fuel combustion because of the higher percentages of $\mathrm{V}$ and $\mathrm{Ni}$, (Fig. 2), which are typical of oil combustion (Huffman et al., 2000; Lee et al., 2000). On average, the ratio of $\mathrm{V}$ to $\mathrm{Ni}$ in this factor profile was 5.5, which was comparable to the heavy oil combustion with high sulfur contents reported by Huffman et al. (2000) $(\mathrm{V} / \mathrm{Ni}=5-7)$. Other elements associated with oil combustion such as $\mathrm{S}, \mathrm{Ti}, \mathrm{Zn}$, and Fe (Huffman et al., 2000; Lee et al., 2000) were also evident. The temporal correlation of this factor to $\mathrm{SO}_{2}$ in the intensive measurement campaign suggested the combustion of high-sulfur fuel (Table 2) (Van Loo and Koppejan, 2008; Zhang et al., 2015). Uncentered correlation $(r=0.99)$ between the chemical profile for this factor and the average element profile seen in upgrader stacks around the region (Landis et al., 2012) was slightly lower than the correlation for the upgrader emissions I factor. In addition, the time series of this factor exhibited short-term peaks that occurred during the intensive measurement campaign at different times than those of the first upgrader emissions factor (Fig. S9). The lower mole ratio of particulate sulfur to $\mathrm{SO}_{2}$ (upgrader emissions I: 0.44; upgrader emissions II: 0.22 ) evaluated during these short-term peaks suggests that while both sources were relatively local, upgrader emissions II may have been closer to the receptor site. This, in addition to the small contribution of this factor relative to that of the first upgrader factor, indicated that this factor may have been due to occasional smaller plumes that occurred for too short a duration or too rarely to be differentiated through the long-term $24 \mathrm{~h}$ filter data. In contrast, the Xact data's time 
Table 2. Spearman correlation $(r)$ of gaseous pollutants with PMF-resolved factors.

\begin{tabular}{lll}
\hline Campaign & Factor & Correlated gases $(r>0.3, p<0.01)$ \\
\hline Long-term filter & Upgrader emissions I & $\mathrm{SO}_{2}(r=0.53), \mathrm{NO}_{2}(r=0.46), \mathrm{NO}_{x}(r=0.41)$ \\
& Soil & None \\
& Haul road dust & None \\
& Mixed sources & None \\
& Biomass burning & $\mathrm{None}$ \\
\hline Intensive & Upgrader emissions I & $\mathrm{SO}_{2}(r=0.64), \mathrm{NO}_{2}(r=0.34), \mathrm{NO}_{x}(r=0.34)$ \\
& Upgrader emissions II & $\mathrm{SO}_{2}(r=0.56)$ \\
& Soil & $\mathrm{SO}_{2}(r=0.36), \mathrm{NO}_{2}(r=0.53), \mathrm{NO}_{x}(r=0.48)$ \\
& Haul road dust & $\mathrm{SO}_{2}(r=0.52), \mathrm{NO}_{2}(r=0.55), \mathrm{NO}_{x}(r=0.49)$ \\
& Mixed sources & $\mathrm{None}$ \\
\hline
\end{tabular}

resolution allowed the isolation of this more specific process/emission occurring as part of the upgrading processes. In this case the upgrader emissions factor for the long-term campaign likely included the upgrader emissions II factor. It is speculated that this factor may have been due to two different stacks from within the upgrading process/facility. A less likely possibility is that the upgrader emissions II factor was due to a short-term change in upgrader fuel that occurred only during the intensive measurement campaign and not during the long-term campaign.

\subsubsection{Soil}

The soil factor exhibited high concentrations of crustal elements such as Si, Ti, and K (Figs. 2 and 3). Additionally, both the filter and the Xact instrument's chemical profiles exhibited a high correlation with samples taken of the area's overburden dump (intensive measurement campaign (uncentered $r=0.99$ ); filter (uncentered $r=0.93$ )) (Landis et al., 2012) which supported identifying this factor as a soil factor. The overburden dump is comprised of the topsoil of the area, a mixture of the soil and glacial till overlying the oil deposits (Landis et al., 2012). The soil factor derived from the longterm campaign data exhibited high concentrations of additional crustal elements not measured by the Xact instrument such as Al and lanthanoids such as Pr, Sm, and Nd (Fig. 3). Interestingly, this factor also exhibited high concentrations of Fe (both campaigns) and $\mathrm{S}$ (intensive campaign). This may have been due to the presence of bitumen in the soil in the Athabasca region or may indicate that this natural crustal material was being aerosolized through anthropogenic means. Specifically, the soil may have been emitted through entrainment by off-road transportation or the crushing of bitumenrich sand. This hypothesis was supported by the high correlation of this factor with $\mathrm{NO}_{2}$ and $\mathrm{NO}_{x}$ (Table 2), which are related to engine emissions (Almeida et al., 2014). In fact, it is probable that this soil factor represents a combination of emissions: (1) directly through entrainment by off-road vehicular traffic on-site and (2) indirectly through "track-out", where the dust temporarily sticks to vehicles traveling within the mining sites, only to be aerosolized on-road later after leaving the site. In summary, the soil factor's chemical profile was consistent with natural soils but its rate of emission may have been enhanced by anthropogenic processes. This factor was identified through both methodologies; the source profiles for the two campaigns and time series between the co-measured Xact and filter data were highly correlated (profile (uncentered $r=0.99$ ); time series (Spearman $r=0.86$, $p<0.01)$ ).

\subsubsection{Haul road dust}

Much like the soil factor, this factor exhibited high concentrations of crustal elements such as $\mathrm{Ca}$ and Fe (Fig. 2), and the PMF outputs derived from the intensive and long-term campaign data were highly correlated to each other (profile (uncentered $r=0.88$ ); time series (Spearman $r=0.80$, $p<0.01)$ ). What differentiated this factor from the soil factor were the higher concentrations of $\mathrm{Mn}, \mathrm{Fe}$, and $\mathrm{Ca}$ (Fig. 2). The strength of the correlations with $\mathrm{NO}_{2}$ and $\mathrm{NO}_{x}$ is indicative of vehicular traffic (Moreno et al., 2013; Almeida et al., 2014). In fact, the source profiles for the soil and haul road dust were only weakly correlated (uncentered $r=0.23$ ). Furthermore, the element profiles of this factor were similar to that of samples taken by WBEA of the Athabasca region's haul road dust (intensive campaign (uncentered $r=0.67$ ); long-term campaign (uncentered $r=0.85)$ ). As haul roads are made of a mixture of overburden material combined with limestone and low-grade oil sand, it is reasonable that the soil and haul road dust factors exhibit some similarities in chemical composition.

\subsubsection{Biomass burning}

Only observed in the long-term campaign, this factor was characterized by its high $\mathrm{S}, \mathrm{K}, \mathrm{Zn}, \mathrm{Br}, \mathrm{Cd}$, and $\mathrm{Pb}$. All of these elements, to different degrees, have been associated with different types of biomass burning in this (Jeong et al., 2011; Kindzierski and Bari, 2015; Bari et al., 2015) and other regions (Van Loo and Koppejan, 2008; Vassura et al., 2014; 
Alves et al., 2011). Furthermore, this combination of elements associated with different types of biomass combustion was consistent with a forest fire (Landis et al., 2012) in which all types of plants are burned. Finally, this factor's profile displayed a high correlation (uncentered $r=0.99$ ) with the measured profile of an Alberta forest fire and in fact experienced its highest peak during a period of intense forest fires in northern Alberta (USDA Forest Service, 2011). Combined, these similarities suggested that this factor originated from biomass burning, with smaller possible contributions year-round from the scrap-brush burning for land clearing that is performed in the area.

\subsubsection{Mixed sources}

The PMF results of each campaign yielded a factor that appeared to be a combination of anthropogenic and crustal sources. While the mixed factors from the two campaigns were not correlated to each other (profile (uncentered $r=$ 0.26 ); time series (Spearman $r=-0.03, p=0.91)$ ), they both appeared to originate from multiple sources. The mixed factor from the intensive measurement campaign was characterized by elements such as $\mathrm{Cu}, \mathrm{Zn}$, and $\mathrm{Mn}$, which suggested the presence of mechanical abrasion (Zhang et al., 2011; Gietl et al., 2010; Bukowiecki et al., 2007), as well as Ni, K and Se, which suggested the inclusion of biomass, oil, or coal burning, perhaps the burning of scrap brush (Van Loo and Koppejan, 2008; De Santiago et al., 2014). In contrast, the marker elements from the long-term campaign included $\mathrm{Zn}, \mathrm{Cu}, \mathrm{K}$, and $\mathrm{Ca}$, suggesting as possible sources mechanical abrasion and activities aerosolizing crustal elements. The conflicting nature of these two different mixed-source factors suggested the presence of further factors. This was further evidenced by the unstable temporal trends these factors exhibited and the relative stability of the alternate six-factor solutions (Fig. S6). For example, some of the characteristic elements identified in the intensive measurement campaign, such as $\mathrm{Br}$ and Se, proved to be less stable and would separate from the intensive measurement campaign's mixed factor when the number of factors was increased (Fig. S6b). However, these six-factor solutions were less stable than the five-factor solutions and did not yield additional, clearer factors. This suggested that these mixed factors were a result of insufficient data that prevented full separation into more distinct source profiles. A more detailed evaluation of the PMF solutions is described in the Supplement. The combination of anthropogenic and crustal elements present in these factors could have arisen from mining-related activities such as mechanical abrasion of excavated materials within crushers. Activities such as combustion-powered mechanical abrasion could result in a full-range of PM, from ultrafine to coarse, part of which would be considered to be $\mathrm{PM}_{2.5}$ (Okuda et al., 2007; Martins et al., 2015). Other elements within these mixed sources could have been the result of further industrial activity at the different plant sites, which are known to be large emitters of elements such as $\mathrm{Ni}, \mathrm{Cu}, \mathrm{Cr}, \mathrm{Zn}$, and $\mathrm{Se}$ (Environment and Climate Change Canada, 2015).

\subsection{Spatial and temporal trends}

After analysis with PMF, the resultant factor time series (G matrix) of the combined filter data was split into three distinct factor time series, one corresponding to each site (AMS5, AMS11, or AMS13), in order to examine both the temporal and spatial trends (Fig. S10). The time-series contributions were then averaged to assess each site's seasonality (Fig. 4) from December 2010 to November 2012. Finally, the factor contributions derived from the Xact data were compared to the averaged contributions from the August 2013 portion of the long-term campaign at AMS13 (Fig. 5).

As can be seen from Fig. 4, there were clear differences in mass contributions between the three sites. Of the three sites, AMS5 consistently exhibited the highest element concentrations, followed by AMS11 and then AMS13, which was largely due to the high amounts of haul road dust measured at AMS5. In contrast, AMS11 had higher average contributions from the upgrader emissions and soil than both AMS5 and AMS13. This can be explained by the prevalent winds at AMS11, which were often from the southeast, the direction of the upgrader processes (Fig. 1). Overall, these local differences between the sites may have been due to a combination of the proximity of the sites to the various emission sources, as well as the direction of the prevailing winds at each site (Fig. S11). In particular, the predominant winds at AMS13 came from the north and the southeast, which point towards the Syncrude and the more distant CNRL mines. In contrast, at AMS5 the wind came from many directions in which there were roads and open mines.

Fig. 4 also depicts the seasonal trends in the five factors identified in the long-term campaign. The total contribution was largest in the spring, then lower in the winter, then summer, and then fall. A major part of this overall trend was due to the higher contribution from biomass burning, a natural source, in the spring. However, even without the inclusion of biomass burning, the combined mass loading of the four remaining factors followed the same overall seasonal trend. Of the five factors, only the mixed factor was relatively consistent throughout the seasons (within $0.08 \mu \mathrm{g} \mathrm{m}^{-3}$ ). Both the soil and the haul road dust factors were notably lower in the winter than in the other seasons, presumably due to freezing of the ground and snow cover in the winter. The concentrations were higher in spring than in fall. In the fall, the temperatures drop below $0^{\circ} \mathrm{C}$ quickly (Fig. S12), which could result in the lower soil and haul road dust concentrations. In contrast, temperatures are higher in the spring (Fig. S12) and there is a surplus of sand on paved roads from ice treatment in the winter. Interestingly, the upgrader emissions factor's contribution to the total $\mathrm{PM}_{2.5}$ mass was highest in the winter and spring, which may be due to the differences in mixing height and wind direction and speeds across the seasons, or 


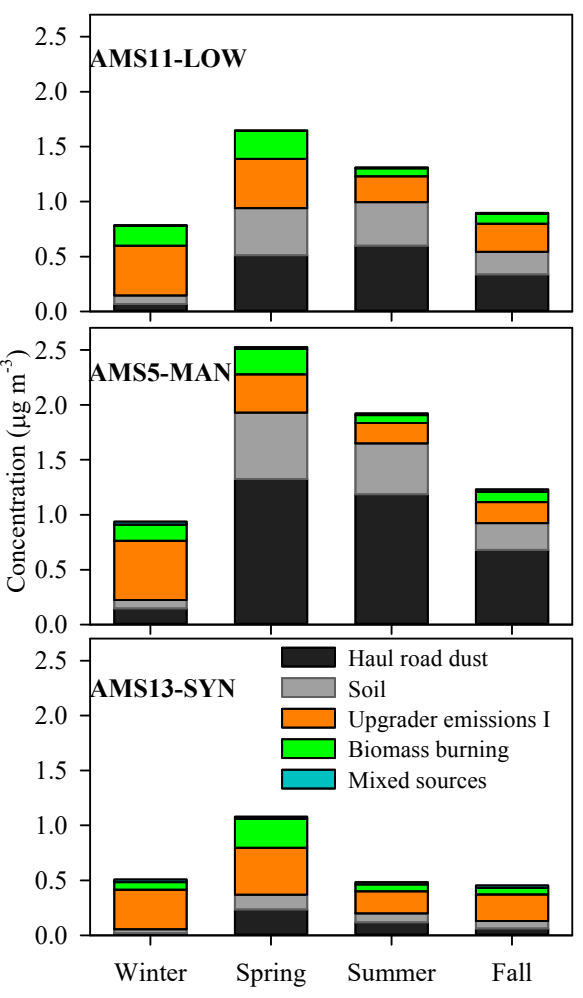

Figure 4. Average seasonal contribution at the three sites from the combined long-term filter campaign data. The contributions are averaged by the season: winter (21 December-19 March), spring (20 March-20 June), summer (21 June-21 September), and fall (22 September-20 December) from 16 December 2010 to 29 November 2012.

it may reflect true changes in upgrader activity. Overall, the combined seasonal concentration of the factors follows the same trend as the strength and directionality of the prevailing winds, in which the most prevalent, fast winds are present in the spring, then winter, then summer, and then fall (Fig. S11).

In addition to the wind speeds, mixing height plays a vital role in the impact of various factors throughout the seasons. In the colder months, inversions can occur, increasing concentrations and channeling emissions horizontally based on the local topography (Davison et al., 1981; Celo and DabekZlotorzynska, 2010). This may result in higher contributions from emissions sources, such as soil and haul road dust, which occur close to the ground. In contrast, in the warmer months, more vertical mixing tends to occur, which may result in the observance of higher contributions from tall emission stacks. Thus, the seasonality apparent within the source contributions is presumably in part due to this seasonality in mixing. However, the low contributions of the soil and haul road dust factor in winter, when mixing is the lowest, are not likely due to low mixing, unless the mixing was so low that it prevents transport from the sources to the nearby measurement sites. This indicates that it is more likely that emissions of soil and haul road dust are lower in winter.

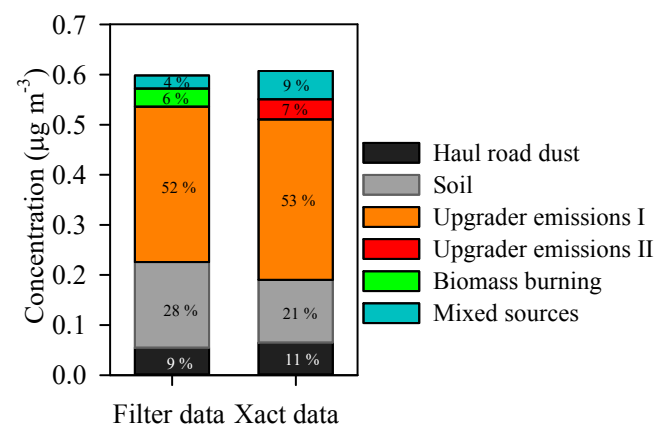

Figure 5. Average mass contributions at AMS13 of each factor derived from the hourly Xact and $23 \mathrm{~h}$ integrated filter data during the intensive campaign from 13 August to 4 September 2013.

A closer look at the contributions during the summer of 2013 is shown in Fig. 5. Good agreement of the upgrader I emissions can be seen between the PMF factor contributions to the total element concentrations calculated from the AMS13 August 2013 filter and hourly data (52 and 53\%, respectively). While there is disagreement between the two independent PMF runs in the magnitude of the contribution from soil and haul road dust $38 \%$ for filter vs. $31 \%$ for Xact), the time series for the soil and haul road dust factor from the filter measurements taken at AMS13 during August 2013 vs. that from the Xact measurements did exhibit good temporal correlations (Spearman $r=0.77$ ). It is possible that the filter data only allowed limited separation of the haul road dust factor from the soil factor: the $24 \mathrm{~h}$ timescale of the filter data would not enable distinguishing changes that occur on a smaller timescale, such as the changing mixing height and/or wind direction throughout the day. Alternatively, by combining the data from the three sites prior to running PMF, the factor contributions may have been biased towards sites more impacted by the crustal factors. Despite these differences in relative contributions, the factors identified by the two different methodologies were broadly similar. Finally, as the filter data measured at AMS13 during August 2013 were added to those measured between December 2010 and November 2012 prior to analyzing it with PMF, the small contribution $(\sim 6 \%)$ of the biomass burning factor seen in this figure arose from the forest fire factor resolved through other times in the long-term campaign, and given its low magnitude it is uncertain if this is an accurate indication of emissions from biomass burning during the intensive measurement campaign.

Whereas the long-term campaign was able to identify the overall seasonal trends in the factors, the lower time resolution made identification of some sources more difficult (Fig. S9). In contrast, the higher time resolution employed during the intensive measurement campaign revealed diurnal patterns (Figs. 6 and S9). From Fig. S9, it is clear that both the upgrader emissions were observed episodically, which indicates that they likely came from specific point sources 


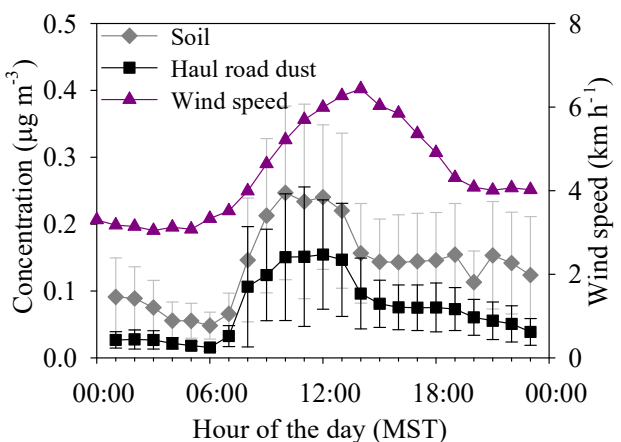

Figure 6. Average concentrations displaying the diurnal trends the soil factor (grey) and the haul road dust factor (black) at AMS13 during the intensive campaign and the average wind speeds between December 2010 and September 2012 (purple). Error bars represent $95 \%$ confidence intervals.

and could thus be measured only when the wind was favorable. Interestingly, both the haul road dust and soil exhibited similar but slightly offset, diurnal trends (Fig. 6). This is in contrast to the daily trends in the mixing height in the area, which are highest during the day and lowest during the night (Davies, 2012). This trend also disagrees with the average diurnal wind speeds that occur at AMS13, which experience their peak at 15:00, while both the soil and the haul road dust factors experienced their highest peaks at 11:00 (Fig. 6). Overall, this suggests that the daytime increases for both the soil and the haul road dust factors were not due to natural processes such as decreases in mixing height or increases in windblown dust. Further, the daytime increase pointed to onroad vehicles (e.g., through track-out) rather than off-road mining activities as the more dominant source, as off-road operations at most mining sites occur around the clock.

In addition to diurnal patterns, the higher time resolution used by the Xact instrument resulted in more detailed CPF plots (Figs. 7 and S13). Whereas the Xact data were able to point towards distinct emission sources with the CPF plots, the filter data time resolution was too low. Despite this, the multiple sites used by the filter study allowed for approximate triangulation of the sources (Fig. S13). The results of the two CPF profiles indicate that both the upgrader I and II emissions came from the direction of known upgraders and that the mixed factors came from the direction of known mines. The haul road dust factor appeared to come from the direction of the three major roads closest to the receptor site(s). Further, the CPF profile of the soil factor exhibited broad peaks which surrounded known mines, perhaps as a result of vehicular traffic leading to and from the mines. Finally, the biomass burning factor appeared to come into the valley from the north and south. Because of this, HYSPLIT analysis was run on the three highest-concentration days for both the biomass burning and the soil factors in order to determine if they were local or regional in origin. The long-range transport of the biomass burning factor, which
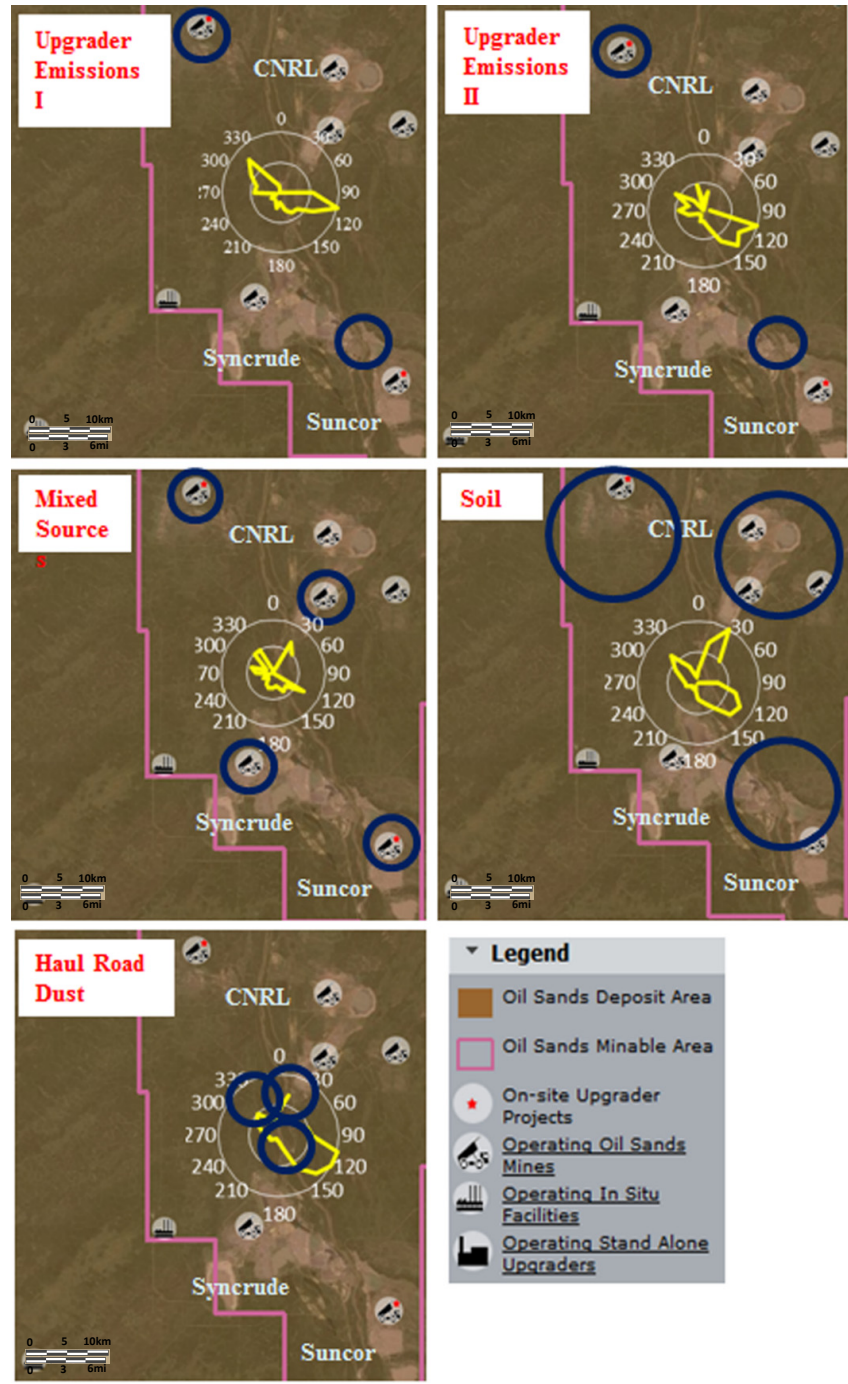

Figure 7. CPF profiles of the five factors identified by hourly Xact data during the intensive campaign in August 2013. Blue circles indicate possible source locations. Map courtesy of Alberta's Environmental and Sustainable Resource Development. Available at http://osip.alberta.ca/map/.

experienced its highest-concentration days during periods of known biomass burning just north of the measurement sites (USDA Forest Service, 2011), appeared to largely come from specific regions in northern Alberta that contained additional forest fires (Fig. S14). Combined, the local and regional forest fires greatly affected the air quality, as during this period (May-June 2011), the average $\mathrm{PM}_{2.5}$ concentration increased by $328 \%$. Back trajectory analysis of the highestconcentration soil days of each receptor site suggested that it predominantly came from the direction of known mines (Fig. S15); these trajectories largely crossed uninhabited, forested, areas in northern Canada prior to reaching the openpit mines. Overall, these finding support the conclusions that the upgrader emissions came from the bitumen upgrading 
process, the soil and the haul road dust factors came from on-road transportation coupled with track-out, and the mixed factors likely originated in the open-pit mines.

\subsection{Long-term vs. intensive-campaign methodologies}

The methodologies employed in the long-term and the intensive campaigns each had their own strengths and weaknesses. The lower DL and higher number of element species measured by the filter samples resulted in more detailed factor profiles (Figs. 2 and 3). Further, the longer duration enabled the identification of seasonal trends, while the use of multiple sampling sites improved the geographic resolution of sources. However, the limited number of co-measured aerosol and gaseous species enabled fewer comparisons. Additionally, the longer $24 \mathrm{~h}$ sampling time of the filter limited the separation of close-proximity sources, such as upgrader emissions I and II.

In contrast, the higher time resolution employed by the Xact instrument resulted in better-defined temporal patterns, which supported the separation of similar sources (Figs. 6 and S9), which in turn led to more precise CPF profiles and gaseous species comparisons (Fig. 7, Table 2). Furthermore, the higher time-resolution measurements accomplished all this within a much shorter time frame. However, without the long-term filter sampling, it would have been unclear how representative this intensive period was of the norm. Because of this, it is important to take more time-resolved element measurements in this area in order to see if there are further, unresolved sources. This is important as it can help to guide decisions made about regulation and control in the area.

In addition to their measurement capabilities, each campaign had its own requirements in terms of energy, difficulty in setup and measurement, and quality control. While the intensive measurements by the Xact instrument had more energy and housing requirements on-site, the filter analysis required much more follow-up laboratory analysis. Finally, despite the quality assurance and control measures employed by the Xact instrument, comparison to co-measured species indicated a possible linear bias in certain elements measured. In contrast, the filter protocol employed was well established and followed stringent quality assurance and quality control protocols. This led to a high level of confidence in these measurements.

\subsection{Implications of the source identification for element species}

Overall, the average concentration of some element species measured in the Athabasca region was either equal to or higher than that measured in urban/industrial locations in Canada (Table S6). In particular, the concentrations of Si, Ti, $\mathrm{K}, \mathrm{Fe}, \mathrm{Ca}$, and $\mathrm{Al}$ were, on average, higher than those measured in major Canadian cities. At their highest peaks the concentrations of $\mathrm{S}, \mathrm{Ba}, \mathrm{Br}$, and $\mathrm{Mn}$ also exhibited large in- creases in concentrations. Of these elements, $\mathrm{Ti}, \mathrm{Fe}, \mathrm{Cu}$, and $\mathrm{Zn}$ all showed periods of higher concentration during the intensive measurement campaign. Of these species, $\mathrm{Al}, \mathrm{Ca}, \mathrm{Si}$, $\mathrm{Mn}, \mathrm{Ba}$, and $\mathrm{Fe}$ were predominantly observed in the soil and haul road dust factors, suggesting that they originated from vehicle-related emissions or associated anthropogenic dust production in the area. These species have been previously seen to be elevated in epiphytic lichens (Landis et al., 2012). The elements $\mathrm{As}, \mathrm{Pb}$, and $\mathrm{Tl}$ were associated with upgrader emissions, and $\mathrm{Be}$ and $\mathrm{Ba}$ were associated with the haul road dust; these metals and metalloids were also previously found to be higher in snow or biota near the oil sands operation (Landis et al., 2012).

There were some differences between the campaign data as to the dominant source(s) of some elements. For example, $\mathrm{V}$ was apportioned to soil and upgrader emissions I in the long-term campaign, while, based on the intensive measurement campaign, it was almost entirely apportioned to the upgrader emissions II factor. While this difference appeared to create some ambiguity it actually highlighted the enhanced separation of factors allowed by the higher time-resolution Xact data: V was associated with a type of anthropogenic emissions that the filter sampling had trouble identifying. Interestingly, $\mathrm{Ni}, \mathrm{Zn}, \mathrm{Cr}, \mathrm{Ag}$, and $\mathrm{Cu}$ were grouped into mixed factors. As these factors represented a combination of multiple sources, the individual sources causing the elevation of these elements is still not known; this limitation may help direct further studies. More generally, the elements used to create the factor profiles and thereby identify sources accounted for only a small portion of the total $\mathrm{PM}_{2.5}$ mass. This limitation will be addressed in a follow-up analysis combining the Xact data with other concurrent, time-resolved, measurements of non-refractory components. Combining these data will provide a more complete mass reconstruction so as to allow the apportionment of $\mathrm{PM}_{2.5}$, and further sources may be revealed by leveraging the perspective given by the additional composition information.

\section{Conclusions}

In conjunction with JOSM, seven sources of $\mathrm{PM}_{2.5}$-related elements were identified through two measurement technologies: two types of upgrader emissions, soil, haul road dust, biomass burning, and two sources of mixed origin. Of the seven factors obtained by the PMF analysis, two were directly associated with oil sands upgrading, two with on- and off-road transportation, one with natural processes, and two with mixed anthropogenic-natural activities. Thus, much of the $\mathrm{PM}_{2.5}$-related elements were found to originate from anthropogenic sources or activities. Interestingly, it was only through the time-resolved measurements taken by the Xact instrument that some of these anthropogenic activities became better defined and understood, which can help guide further studies. This work describes the influence of the de- 
velopment activities on PM in the part of the Athabasca oil sands region near open-pit mining and upgrading activities. Finally, determining the relative contributions of these sources to the different elements in $\mathrm{PM}_{2.5}$, helped to better resolve their potential contributions to the higher concentrations of elements in snow, water, and biota that have been previously reported for samples collected near the oil sands operations.

Data availability. Data are available at the Canada-Alberta Oil Sands Environmental Monitoring Information Portal: http:// jointoilsandsmonitoring.ca/default.asp?lang=En\&n=A743E65D- 1 (Canada-Alberta Oil Sands, 2017).

\section{The Supplement related to this article is available online at https://doi.org/10.5194/acp-17-9435-2017-supplement.}

Competing interests. The authors declare that they have no conflict of interest.

Special issue statement. This article is part of the special issue "Atmospheric emissions from oil sands development and their transport, transformation and deposition (ACP/AMT inter-journal SI)". It is a result of the Joint Oil Sands Monitoring (JOSM) program of the governments of Canada and the province of Alberta, Canada, 2012.

Acknowledgements. This study was undertaken with the financial and operational support of the Government of Canada through Environment and Climate Change Canada as part of the Joint Canada-Alberta Implementation Plan for Oil Sands Monitoring program. Infrastructure support was provided by the Canada Foundation for Innovation and the Ontario Research Fund (Project: 19606). The authors thank the Wood Buffalo Environmental Association (WBEA) for support in integrated air sampling collection in the Athabasca oil sands region. We would like also to acknowledge the provincial, territorial, and municipal governments as partners of the National Air Pollution Surveillance (NAPS) Program.

Edited by: Shao-Meng Li

Reviewed by: three anonymous referees

\section{References}

Alfoldy, B., Giechaskiel, B., Hofmann, W., and Drossinos, Y.: Sizedistribution dependent lung deposition of diesel exhaust particles, J. Aerosol Sci., 40, 652-663, 2009.

Almeida, S., Silva, A., Garcia, S., Henriques, E., and Miranda, M.: Traffic-related air pollution in an industrial area, WIT Trans. Ecol. Environ., 181, 683-694, 2014.
Alves, C., Vincente, A., Nunes, T., Goncalves, C., Fernandes, A., Mirante, F., Tarelho, L., Sánchez de la Campa, A., Querol, X., Caseiro, A., Monteiro, C., Evtyugina, M., and Pio, C.: Summer 2009 wildfires in Portugal; Emission of trace gases and aerosol composition, Atmos. Environ., 45, 641-649, 2011.

Amato, F., Karanasiou, A., Cordoba, P., Alastuey, A., T., M., Lucarelli, F., Nava, S., Calzolai, G., and Querol, X.: Effects of road dust suppressants on PM levels in a Mediterranean urban area, Environ. Sci. Technol., 48, 8069-8077, 2014.

Amodio, M., Catino, S., Dambruoso, P., Di Gilio, A., Giungato, P., Laiola, E., Marzocca, A., Mazzone, A., and Tutino, M.: Atmospheric deposition: Sampling procedures, analytical methods, and main recent findings from the scientific literature, Adv. Meteorol., 2014, 1-27, https://doi.org/10.1155/2014/161730, 2014.

Bari, M. and Kindzierski, W.: Fifteen-year trends in criteria air pollutants in oil sands communities of Alberta, Canada, Environ. Int., 74, 200-208, 2015.

Bari, M. and Kindzierski, W.: Ambient fine particulate matter $\left(\mathrm{PM}_{2.5}\right)$ in Canadian oil sands communities: Levels, sources and potential human health risk, Sci. Total Environ., 595, 828-838, 2017.

Bari, M., Kindzierski, W., and Cho, S.: A wintertime investigation of atmospheric deposition of metals and polycyclic aromatic hydrocarbons in the Athabasca Oil Sands Region, Canada, Sci. Total Environ., 485-486, 180-192, https://doi.org/10.1016/j.scitotenv.2014.03.088, 2014.

Bari, M., Kindzierski, W. B., Wallace, L. A., Wheeler, A. J., MacNeill, M., and Héroux, M.-È.: Indoor and outdoor levels and sources of submicron particles $\left(\mathrm{PM}_{1}\right)$ at homes in Edmonton, Canada, Environ. Sci. Technol., 49, 6419-6429, 2015.

Becagli, S., Sferlazzo, D. M., Pace, G., di Sarra, A., Bommarito, C., Calzolai, G., Ghedini, C., Lucarelli, F., Meloni, D., Monteleone, F., Severi, M., Traversi, R., and Udisti, R.: Evidence for heavy fuel oil combustion aerosols from chemical analyses at the island of Lampedusa: a possible large role of ships emissions in the Mediterranean, Atmos. Chem. Phys., 12, 3479-3492, https://doi.org/10.5194/acp-12-3479-2012, 2012.

Borm, P. and Kreyling, W.: Toxicological hazards of inhaled nanoparticles-Potential implications for drug delivery, J. Nanosci. Nanotechnol., 4, 521-531, 2004.

Brown, S. G., Eberly, S., Paatero, P., and Norris, G. A.: Methods for estimating uncertainty in PMF solutions: Examples with ambient air and water quality data and guidance on reporting PMF results, Sci. Total Environ., 518, 626-635, 2015.

Bukowiecki, N., Gehrig, R., Hill, M., Lienenmann, P., Zwicky, C., Buchmann, B., Weingartner, E., and Baltensperger, U.: Iron, manganese and copper emitted by cargo and passenger trains in Zurich (Switzerland): Size-segregated mass concentrations in ambient air, Atmos. Environ., 41, 878-889, 2007.

Burnett, R., Dales, R., Krewski, D., Vincent, R., Dann, T., and Brook, J.: Associations between ambient particulate sulphate and admissions to Ontario hospitals for cardiac and respiratory diseases, Am. J. Epidemiol., 142, 15-22, 1995.

Bytnerowicz, A., Fraczek, W., Schilling, S., and Alexander, D.: Spatial and temporal distribution of ambient nitric acid and ammonia in the Athabasca Oil Sands Region, Alberta, J. Limnol., 69, 1121, 2010 .

Canada-Alberta Oil Sands: Ground-based measurements of air pollutants and meteorology during the summer 2013 campaign 
in the Oil Sands Region, available at: http://www.ec.gc.ca/ data_donnees/SSB-OSM_Air/AmbientGasesAndParticles/

GroundBasedMeasurements-Summer2013/, last access: 31 July 2017.

Canadian Association of Petroleum Producers: What are Oil Sands?, Canadian Association of Petroleum Producers, available at: http://www.capp.ca/canadaIndustry/oilSands/ Energy-Economy/Pages/what-are-oilsands.aspx (last access: 31 May 2016), 2014.

Celo, V. and Dabek-Zlotorzynska, E.: Concentration and source origin of trace metals in $\mathrm{PM}_{2.5}$ collected at selected Canadian sites within the Canadian National Air Pollution Surveillance Program, in: Urban Airborne Particulate Matter, edited by: Zereini, F. and Wiseman, C., Springer-Verlag, Berlin, 19-38, 2010.

Celo, V., Dabek-Zlotorzynska, E., Zhao, J., Okonskaia, I., and Bowman, D.: An improved method for determination of lanthanoids in environmental samples by inductively coupled plasma mass spectrometry with high matrix introduction system, Anal. Chim. Acta, 706, 89-96, 2011.

Charpentier, A. and Bergerson, J. M.: Understanding the Canadian oil sands industry's greenhouse gas emissions, Environ. Res. Lett., 4, 014005, https://doi.org/10.1088/1748-9326/4/1/014005, 2009.

Cho, S., McEachern, P., Morris, R., Shah, T., Johnson, J., and Nopmongcol, U.: Emission sources sensitivity study for ground-level ozone and $\mathrm{PM}_{2.5}$ due to oil sands development using air quality modeling system: Part 1 - model evaluation for current year base case simulation, Atmos. Environ., 55, 533-541, 2012.

Davies, M.: Chapter 12 - Air Quality Modeling in the Athabasca Oil Sands Region, in: Alberta Oil Sands: Energy, Industry and the Environment, edited by: Percy, K., Elselvier Ltd., 267-309, 2012.

Davison, D., Davies, M., Rudolph, R., and Hansen, M.: Airshed Management System for the Alberta Oil Sands, In Verification and Sensitivity Studies Volume III, INTERA Environmental Consultants Ltd., 1981.

De Santiago, A., Longo, A., Ingall, E., Diaz, J., King, L., Lai, B., Weber, R. J., Russell, A. G., and Oakes, M.: Characterization of selenium in ambient aerosols and primary emission sources, Environ. Sci. Technol., 48, 8988-8994, 2014.

Docker, D. W., Pope, C. A., Xu, X., Spengler, J. D., Ware, J. H., Fay, M. E., Ferris, B. G., and Speizer, F. E.: An association between air pollution and mortality in six U.S. cities, New Engl. J. Med., 329, 1753-1759, 1993.

Dusek, U., Franks, G., Hildebrandt, L., Curtius, J., Schneider, J., Walter, S., Chand, D., Drewnick, F., Hings, S., Jung, D., Borrmann, S., and Andreae, M.: Size matters more than chemistry for cloud-nucleating ability of aerosol particles, Science, 312, 1375-1378, 2006.

Environment and Climate Change Canada: NAPS Data Products, available at: http://maps-cartes.ec.gc.ca/rnspa-naps/data. aspx?lang=en, last access: 15 July 2015.

Gietl, J., Lawrence, R., Thorpe, A., and Harrison, R.: Identification of brake wear particles and derivation of a quantitative tracer for brake dust at a major road, Atmos. Environ., 44, 141-146, 2010.

Goff, K. L., Headley, J. V., Lawrence, J. R., and Wilson, K. E.: Assessment of the effects of oil sands napthenic acid on the growth and morphology of Chlamydomonas reinhardtii using micro- scopic and spectromicroscopic techniques, Sci. Total Environ., 442, 116-122, 2013.

Healy, R. M., Riemer, N., Wenger, J. C., Murphy, M., West, M., Poulain, L., Wiedensohler, A., O'Connor, I. P., McGillicuddy, E., Sodeau, J. R., and Evans, G. J.: Single particle diversity and mixing state measurements, Atmos. Chem. Phys., 14, 6289-6299, https://doi.org/10.5194/acp-14-6289-2014, 2014.

Hodson, P. V.: History of environmental contamination by oil sands extraction, P. Natl. Acad. Sci. USA, 110, 1569-1570, 2013.

Howell, S. G., Clarke, A. D., Freitag, S., McNaughton, C. S., Kapustin, V., Brekovskikh, V., Jimenez, J.-L., and Cubison, M. J.: An airborne assessment of atmospheric particulate emissions from the processing of Athabasca oil sands, Atmos. Chem. Phys., 14, 5073-5087, https://doi.org/10.5194/acp-145073-2014, 2014.

Hsu, Y.-M. and Clair, T. A.: Measurement of $\mathrm{PM}_{2.5}$ water-soluble inorganic species and precursor gases in the Alberta Oil Sands Region using an improved semi-continuous monitor, J. Air Waste Manage. Assoc., 65, 425-435, 2015.

Huffman, G. P., Huggins, F., Shah, N., Huggins, R., Linak, W., Miller, C., Pugmire, R., Meuzelaar, H., Seehra, M., and Manivannan, A.: Characterisation of fine particulate matter produced by the combustion of residual fuel oil, J. Air Waste Manage., 50, 1106-1114, 2000.

Jeong, C.-H., McGuire, M. L., Herod, D., Dann, T., DabekZlotorzynska, E., Wang, D., Ding, L., Celo, V., Mathieu, D., and Evans, G. J.: Identification of sources of $\mathrm{PM}_{2.5}$ at five urban sites across Canada, Atmos. Poll. Res., 2, 158-171, 2011.

Jeong, C.-H., Herod, D., Dabek-Zlotorzynska, E., Ding, L., McGuire, M., and Evans, G.: Identification of the sources and geographic origins of black carbon using factor analysis at paired rural and urban sites, Environ. Sci. Technol., 47, 8462-8470, https://doi.org/10.1021/es304695t, 2013.

Jeong, C.-H., Wang, J. M., and Evans, G. J.: Source Apportionment of Urban Particulate Matter using Hourly Resolved Trace Metals, Organics, and Inorganic Aerosol Components, Atmos. Chem. Phys. Discuss., https://doi.org/10.5194/acp-2016-189, 2016.

Kean, S.: Eco-Alchemy in Alberta, Science, 326, 1052-1055, 2009.

Kelly, E., Schindler, D., Hodson, P., Short, J., Radmanovich, R., and Nielsen, C.: Oil sands development contributes elements at low concentrations to the Athabasca River and its tributaries, P. Natl. Acad. Sci. USA, 107, 16178-16183, 2010.

Kim, E. and Hopke, P.: Comparison between conditional probability function and nonparametric regression for fine particle source directions, Atmos. Environ., 38, 4667-4673, 2004.

Kindzierski, W. and Bari, M.: Long-term temporal trends and influence of criteria pollutants on regional air quality in Fort McKay, Alberta, in: Proceedings of the IASTED International Conference on Unconventional Oils and the Environment, 46 July 2011, Calgary, Alberta, 162-168, 2011.

Kindzierski, W. and Bari, M.: Air quality in Alberta oil sands community of Fort McKay compared to urban residential locations in Canada in 2009, in: Proceedings of the Canadian Society for Civil Engineers 2012, Leadership in Sustainable Infrastructure, Edmonton, AB, 974-983, 2012.

Kindzierski, W. and Bari, M.: Investigation of fine particulate matter characteristics and sources in Edmonton, Alberta, Final Report, University of Alberta, Edmonton, Alberta, 2015. 
Landis, M., Pancras, J., Graney, J., Stevens, R., Percy, K., and Krupa, S.: Receptor modeling of epiphytic lichens to elucidate the sources and spatial distribution of inorganic air pollution in the Athabasca Oil Sands Region, in: Alberta Oil Sands: Energy, Industry and the Environment, edited by: Percy, K. E., Elsevier, 427-467, 2012.

Landis, M., Patrick Pancras, J., Graney, J., White, E., Edgerton, E., Legge, A., and Percy, K.: Source apportionment of ambient fine and coarse particulate matter at the Fort McKay community site, in the Athabasca Oil Sands Region, Alberta, Canada, Sci. Total Environ., 584-585, 105-117, 2017.

Lee, S., Pomalis, R., and Kan, B.: A new methodology for source characterization of oil combustion particulate matter, Fuel Process. Technol., 65-66, 189-202, 2000.

Martins, V., Moreno, T., Minguillon, M., Amato, F., Miguel, E. D., Capdevila, M., and Querol, X.: Exposure to airborne particulate matter in the subway system, Sci. Total Environ., 511, 711-722, 2015.

McLinden, C. A.: Air quality over the Canadian oil sands: A first assessment using satellite observations, Geophys. Res. Lett., 39, L04804, https://doi.org/10.1029/2011GL050273, 2012.

McMaster, M., Evans, M., Alaee, M., Muir, D., and Hweitt, L.: Northern rivers ecosystem initiative: distribution and effects of contaminants, Environ. Monit. Assess, 113, 143-165, 2006.

Moreno, T., Querol, X., Alastuey, A., and Gibbons, W.: Identification of chemical racers in the characterization and source apportionment of inhalable inorganic airborne particle: an overview, Biomarkers, 14, 17-22, 2009.

Moreno, T., Karanasiou, A., Amato, F., Lucarelli, F., Nava, S., Calzolai, G., Chiari, M., Coz, E., Artíñano, B., Lumbreras, J., Borge, R., Boldo, E., Linares, C., Alastuey, A., Querol, X., and Gibbons, W.: Daily and hourly sourcing of metallic and mineral dust in urban air contaminated by traffic and coal-burning emissions, Atmos. Environ., 68, 33-44, 2013.

Moritis, G.: Innovations push bitumen mining, economics; cut environmental costs, Oil and Gas Journal, 108, 88-97, 2010.

Norris, G. and Duvall, R.: EPA Positive Matrix Factorization (PMF) 5.0: Fundamentals and User Guide, Petaluma, CA, United States of America Environmental Protection Agency, 2014.

Okuda, T., Nakao, S., Katsuno, M., and Tanaka, S.: Source identification of nickel in TSP and $\mathrm{PM}_{2.5}$ in Tokyo, Japan, Atmos. Environ., 41, 7642-7648, 2007.

Paatero, P.: User's Guide for Positive Matrix Factorization Programs, PMF2.EXE and PMF3.EXE, University of Helsinki, Helsinki, 1996.

Paatero, P. and Tapper, U.: Analysis of different modes of factor analysis as least squares fit problems, Chemometr. Intell. Lab., 18, 183-194, 1993.

Paatero, P. and Tapper, U.: Positive matrix factorization: a nonnegative factor model with optimal utilization of error estimates of data values, Environmetrics, 5, 111-123, 1994.

Paatero, P., Eberly, S., Brown, S. G., and Norris, G. A.: Methods for estimating uncertainty in factor analytic solutions, Atmos. Meas. Tech., 7, 781-797, https://doi.org/10.5194/amt-7781-2014, 2014.

Percy, K., Hansen, M., and Dann, T.: Air quality in the Athabasca Oil Sands Region 2011, in: Alberta Oil Sands: Energy, Industry, and the Environment, Elsevier Press, Amsterdam, the Netherlands, 47-91, 2012.
Posfai, M. and Buseck, P.: Nature and climate effects of individual tropospheric aerosol particles, Annu. Rev. Earth Planet. Sc., 1743, 2010.

Schlesinger, R.: The health impact of common inorganic components of fine particulate matter $\left(\mathrm{PM}_{2.5}\right)$ in ambient air: A critical review, Inhal. Toxicol., 19, 811-832, 2007.

Shotyk, W., Bicalho, B., Cuss, C., Duke, M., Noernberg, T., Pelletier, R., Pelletier, R., and Zaccone, C.: Dust is the dominant source of "heavy metals" to peat moss (Sphagnum fuscum) in the bogs of the Athabasca Bituminous Sands region of northern Alberta, Environ. Int., 92-92, 494-506, 2016.

Sofowote, U., Rastogi, A., Debosz, J., and Hopke, P.: Advanced receptor modeling of near-real-time, ambient $\mathrm{PM}_{2.5}$ and its associated components collected at an urban-industrial site in Toronto, Ontario, Atmos. Poll. Res., 5, 13-23, 2014.

Stein, A. F., Draxler, R. R, Rolph, G. D., Stunder, B. J. B., Cohen, M. D., and Ngan, F.: NOAA's HYSPLIT atmospheric transport and dispersion modeling system, B. Am. Meteorol. Soc., 96, 2059-2077, https://doi.org/10.1175/BAMS-D-14$00110.1,2015$.

Syncrude Canada Ltd.: Mining the oil sands, available at: http:// www.syncrude.ca/our-process/understanding-our-process/, last access: 31 July 2017.

USDA Forest Service: Remote Sensing Applications Center, Fire Detection Maps, available at: https://fsapps.nwcg.gov/ activefiremaps.php?sensor $=$ modis $\& o p=$ maps $\&$ rCode $=c g b$ (last access: 31 July 2017), 2011.

Van Loo, S. and Koppejan, J.: The handbook of biomass combustion and co-firing, London, UK, Earthscan, 2008.

Vassura, I., Venturini, E., Marchetti, S., Piazalunga, A., Bernardi, E., Fermo, P., and Passarini, F.: Markers and influence of open biomass burning on atmospheric particle size and composition during a major bonfire event, Atmos. Environ., 82, 218-225, 2014.

Wang, X. L., Watson, J. G., Chow, J. C., Kohl, S. D., Chen, L.-W., Sodeman, D. A., Legge, A. H., and Percy, K. E.: Measurement of real-world stack emissions with a dilution sampling system. In Alberta Oil Sands: Energy, Industry, and the Environment, Elsevier Press, Amsterdam, the Netherlands, 171-912, 2012.

Wang, X. L., Chow, J., Kohl, S., Yatavelli, L., Percy, K., Legge, A., and Watson, J.: Wind erosion potential for fugitive dust sources in the Athabasca Oil Sands Region, Aeolian Res., 18, 121-134, 2015.

Whitfield, C., Aherne, J., and Watmough, S.: Modeling soil acidification in the Athabasca Oil Sands region, Alberta, Canada, Environ. Sci. Technol., 43, 5844-5850, 2009.

$\mathrm{Xu}, \mathrm{C}$. and Bell, L.: Worldwide reserves, oil production post modest rise, Oil and Gas Journal, 111, 30-33, 2013.

Zhang, Q., Quan, J., Tie, X., Li, X., Liu, Q., Gao, Y., and Zhao, D.: Effects of meteorology and secondary particle formation on visibility during heavy haze events in Beijing, China, Sci. Total Environ., 502, 578-584, 2015.

Zhang, W., Jiang, H., Dong, C., Yan, Q., Yu, L., and Yu, Y.: Magnetic and geochemical characterization of iron pollution in subway dusts in Shanghai, China, Geochem. Geophy. Geosy., 12, Q06Z25, https://doi.org/10.1029/2011GC003524, 2011. 